\title{
Neuroimaging investigation of memory changes in migraine: a systematic review
}

\author{
Investigação por neuroimagem das alterações de memória na enxaqueca: \\ uma revisão sistemática
}

\author{
Mirian Celly Medeiros Miranda DAVID', Bárbara Sousa dos SANTOS², Waleska Maria Almeida BARROS', \\ Taynara Rayane Lins da SILVA3, Carlúcia Ithamar Fernandes FRANCO², Rhowena Jane Barbosa de MATOS 1,4
}

\begin{abstract}
Background: Individuals with migraine usually complain about lower memory performance. Diagnostic methods such as neuroimaging may help in the understanding of possible morphologic and functional changes related to the memory of those individuals. Therefore, the aim of this review is to analyze the available literature on neuroimaging changes related to memory processing in migraine. Methods: We searched the following databases: Pubmed/Medline, Psycinfo, Science Direct, Cochrane and Web of Science. We used articles without restriction of year of publication. The combination of descriptors used for this systematic review of literature were Neuroimaging OR Imaging OR Brain AND Migraine OR Chronic Migraine AND Memory. Results: Of the 306 articles found, nine were selected and all used magnetic resonance imaging (MRI). The studies used structural and functional MRI techniques with a predominance of 3 Tesla equipment and T1-weighted images. According to the results obtained reported by these studies, migraine would alter the activity of memory-related structures, such as the hippocampus, insula and frontal, parietal and temporal cortices, thereby suggesting a possible mechanism by which migraine would influence memory, especially in relation to the memory of pain. Conclusions: Migraine is associated to global dysfunction of multisensory integration and memory processing. This condition changes the activity of structures in various regions related to memory of pain, prospective memory, as well as in short- and long-term verbal and visuospatial memories. However, it is necessary to perform studies with larger samples in association with cognitive tests, and without the interference of medications to verify possible alterations and to draw more concrete conclusions.
\end{abstract}

Keywords: Headache; Diagnostic imaging; Brain; Cognition; Health evaluation; Magnetic resonance imaging.

\begin{abstract}
RESUMO
Introdução: Indivíduos com enxaqueca geralmente se queixam de menor desempenho de memória. Métodos de diagnóstico como a neuroimagem podem auxiliar no entendimento de possíveis alterações morfológicas e funcionais relacionadas à memória desses indivíduos. Portanto, o objetivo desta revisão é analisar a literatura disponivel sobre alterações de neuroimagem relacionadas a alterações de memória na enxaqueca. Métodos: Pesquisou-se nas seguintes bases de dados: PubMed/MEDLINE, Psycinfo, Science Direct, Cochrane e Web of Science. Foram utilizados artigos sem restrição de ano de publicação. A combinação dos descritores utilizados para esta revisão sistemática da literatura foram Neuroimaging OR Imaging OR Brain AND Migraine OR Chronic Migraine AND Memory. Resultados: Dos 306 artigos encontrados, nove foram selecionados e todos utilizaram ressonância magnética (RM). Os estudos utilizaram as técnicas de RM estrutural e funcional com predomínio de equipamentos de 3 Tesla e imagens ponderadas em T1. De acordo com os resultados obtidos nos estudos, a enxaqueca alteraria a atividade de estruturas relacionadas à memória, como o hipocampo, a ínsula e os córtices frontal, parietal e temporal, sugerindo um possível mecanismo pelo qual a enxaqueca influenciaria a memória, especialmente em relação à memória da dor. Conclusões: A enxaqueca está associada à disfunção global da integração multissensorial e processamento de memória. Essa condição altera a atividade de estruturas em várias regiões relacionadas à memória da dor, à memória prospectiva, bem como às memórias verbais e visuais-espaciais de curto e longo prazo. No entanto, é necessário realizar estudos com amostras maiores em associação com testes cognitivos, e sem a interferência de medicamentos para verificar possíveis alterações e tecer conclusões mais concretas.
\end{abstract}

Palavras-chave: Cefaleia; Diagnóstico por imagem; Encéfalo; Cognição; Avaliação em Saúde; Imagem por ressonância magnética.

\footnotetext{
'Universidade Federal de Pernambuco, Programa de Pós-Graduação em Neuropsiquiatria e Ciências do Comportamento, Recife PE, Brazil.

${ }^{2}$ Universidade Estadual da Paraíba, Departamento de Fisioterapia, Campina Grande PB, Brazil.

${ }^{3}$ Universidade Escritor Osman da Costa Lins, Vitória de Santo Antão PB, Brazil.

${ }^{4}$ Universidade Federal de Pernambuco, Centro Acadêmico de Vitória, Núcleo de Educação Física e Ciências do Esporte, Vitória de Santo Antão PB, Brazil. Mírian Celly Medeiros Miranda DAVID (ID https://orcid.org/0000-0002-7152-8852; Bárbara Sousa dos SANTOS (ID https://orcid.org/0000-0002-0987-9520; Waleska Maria Almeida BARROS (D) https://orcid.org/0000-0002-9033-8165; Taynara Rayane Lins da SILVA (DD https://orcid.org/0000-0002-2396-5847; Carlúcia Ithamar Fernandes FRANCO (D) https://orcid.org/0000-0001-6653-8864; Rhowena Jane Barbosa de MATOS (DD https://orcid.org/0000-0001-5914-7304 Correspondence: Mírian Celly Medeiros Miranda David; E-mail: miriancelly@hotmail.com

Conflict of interest: The authors declare there is no conflict of interest.
}

Support: Research received no specific grant from any funding agency in the public, commercial, or non-profit sectors.

Registration on International Prospective Register of Systematic Reviews (PROSPERO): CRD42018096857.

Received on August 19, 2019; Received in its final form on February 10, 2020; Accepted on February 17, 2020. 
According to the World Health Organization (WHO) data released in 2016, 50-75\% of individuals aged 18-65 years had at least one headache crisis per year in the world, $30 \%$ of them reporting migraine attacks ${ }^{1}$. Individuals with migraine have mild cognitive impairment, mainly regarding attention; visuospatial and verbal memories; processing speed; and executive functions ${ }^{2,3,4}$. Although the worst performance in cognitive tests occurs during migraine attacks, cognitive changes are also present in the interictal period ${ }^{2,3}$.

Such cognitive dysfunctions would be the consequence of the pain processing and not only exclusive for migraine, but also for other types of pain ${ }^{5,6,7}$. Because of the overlapping that exists between the neuroanatomical and neurochemical substrates implicated in pain and cognition, the pain processing would compete with the cognitive functioning, thus affecting the memory performance ${ }^{7,8,9,10}$. In this way, pain affects both coding and recovery of common explicit memory ${ }^{11}$.

Cognitive impairment is influenced by the frequency and duration of migraine crises ${ }^{12}$, that is, having a high frequency of attacks (for example, 4-5 times/week), significantly decreases cognitive performance. This notion is supported by clinical evidence, which shows that individuals with higher frequency of attacks and with a prolonged history of migraine are more prone to present cognitive impairment ${ }^{4}$.

For example, in a recent multicenter study conducted in Brazil, which analyzed cognitive performance of 1,239 migraine sufferers $(79.3 \%$ with episodic and $20.7 \%$ with chronic migraine) measured by several cognitive tests, including the Consortium to Establish the Registry for Alzheimer's Disease word list memory test (CERAD-WLMT), Semantic Fluency Test (SFT), and Trail Making Test version B (TMTB). The authors concluded that individuals suffering from migraine, especially migraine without aura, presented worse cognitive performance when compared to controls ${ }^{13}$.

These results strongly suggest the existence of an association between migraine suffering and a poor cognitive performance, which would be caused by a plethora of disturbances on specific brain areas related with pain coding/integration/ sensation and memory formation. However, the brain areas involved in this "association" still need better characterization. On this regard, neuroimaging techniques have proven to be powerful and useful methods to identify brain activity patterns and anatomical relations with behavioral outputs.

Concerning memory function, this can be divided into several types, presenting multiple brain systems ${ }^{14}$. From this, different brain regions process different types of memory ${ }^{15}$. For example, the hippocampus and striatum process different types of memory, whereas the amygdala modulates its consolidation by regulating memory processing in these regions ${ }^{16}$. Despite the existence of several systems for different types of memory, such systems interact with one another in some situations ${ }^{14}$.

Thus, memory can be classified as to retention time: if it lasts fractions of seconds to a few seconds, it is called immediate memory; if it lasts minutes to hours, it is called short-term memory; if it is consolidated, it is called longterm memory. In addition, memory can also be subdivided according to its nature: declarative or explicit memory; nondeclarative or implicit memory; and working memory ${ }^{17}$. The explicit memory type refers to facts records (semantic memory) and events (episodic memory) that are consciously accessible, such as: when?, where? and who?. On the other hand, implicit memory is characterized by perceptual representation, procedures (motor skills not consciously expressed, such as driving a car), associative (associates two or more stimuli; or one stimulus to a certain response), nonassociative (attenuates a response or sensitizes it by repeating the same stimulus). Working memory, in turn, is involved with reasoning and planning ${ }^{17}$. Among these types of memory, the implicit associative memory has been identified as a contributor to the development of chronic pain, especially in terms of pain memory (painful stimuli generate maladaptative neuroplastic alterations, forming long-term memory and facilitating pain evocation) ${ }^{11,18}$.

Recalling pain is important for assessing, classifying, and treating the condition ${ }^{19}$. However, remembering painful events may influence future pain-related experiences by altering related expectations, emotions, and cognitive processes ${ }^{20}$. Therefore, it has been suggested that neural centers involved in sensory and/or affective property of pain sensation overlap memory centers, thus sharing common neural pathways. The anterior cingulate cortex, insular cortex and the amygdala are examples of regions related to pain and memory ${ }^{21}$. This implies that 1) there is efferent/afferent communication between different brain areas related to pain, emotion and cognitive behavior; or 2) different brain regions share common functions. These questions start to be answered using neuroimaging techniques.

Memory impairment of individuals suffering from migraine can be explained, for example, by changes in the activity pattern of the basal ganglia and hippocampus as seen with neuroimaging and specific cognitive tests ${ }^{22,23}$. Several neuroimaging studies including magnetic resonance imaging and positron emission tomography demonstrate that different brain areas are altered in the pathophysiology of migraine ${ }^{24}$, explaining that associations with the cortical spreading depression hypothesis have been postulated. This theory points out that the cortical spreading depression is a slowly propagating wave of depolarization followed by suppression of brain activity, which promotes expressive alterations in neuronal, glial and vascular functions ${ }^{24}$. Among other structures, this phenomenon would directly affect the hippocampal functioning; and, indirectly, through the entorhinal cortex, altering the signal processing in the hippocampus ${ }^{25,26,27}$.

In this scenario, neuroimaging studies are useful in observing general structural and functional changes in the brain (including the repercussion of the cortical spreading 
depression $)^{28,29,30,31}$. Among the techniques, MRI is one of the most used in diagnoses ${ }^{32}$. Brain imaging studies have revealed that patients suffering from migraine show alterations in diffuse cerebral regions involved in the pain processing in ictal and interictal periods of the attacks. In addition, changes in cerebral connectivity among regions mediating sensory functions in the affective and cognitive components of pain in these individuals have been observed ${ }^{31}$.

Despite this context, there is still no consensus regarding the possible mechanisms related to memory-processing alterations in individuals who suffer from migraine ${ }^{5}$. Therefore, we hypothesize that diagnostic methods, such as neuroimaging, may help to understand the possible morphofunctional changes related to the memories of individuals suffering from migraine. Thus, we aimed to analyze the neuroimaging changes related to memory function in migraine patients published in the scientific literature.

\section{METHODS}

This study is a Systematic Review registered in the International prospective register of systematic reviews PROSPERO (CRD42018096857). This study was developed according to the Cochrane Handbook ${ }^{33}$ and the Preferred Reporting Items for Systematic Reviews and Meta-Analyzes (PRISMA) statement ${ }^{34}$.

The review was developed during May and June 2018, with the following guiding question: Are there neuroimaging changes in regions responsible for the memory of individuals suffering from migraine? To answer this question, the acronym PECOS (Patient, Exposure, Control, Outcome, Study) was used to guide the review (P: individuals diagnosed with migraine, E: Neuroimaging techniques, C: individuals who do not suffer from migraine, O: Neuroimaging changes in structures related to memory, S: Cross-sectional studies).

The studies were searched in the following databases: PubMed/MEDLINE, Psycinfo, Science Direct, Cochrane and Web of Science. Articles were selected without restrictions as to the year of publication or language. The combination of descriptors used for this systematic review of literature were: Neuroimaging OR Imaging OR Brain AND Migraine OR Chronic Migraine AND Memory.

The inclusion criteria considered were:

1. original neuroimaging articles that addressed structural or functional changes related directly or indirectly to the memory of individuals suffering from migraine;

2. studies with adults aged between 18 and 65 years, diagnosed with episodic or chronic migraine;

3. presence of at least one control group of healthy individuals.

Articles were excluded if they were:

1. incomplete or unpublished;
2. animal studies;

3. research protocol articles.

An effort to include all available studies was made, including contact with authors.

The search and selection of articles according to the eligibility criteria was done independently by two evaluators (MD and BS). In case of disagreement, they discussed and reached a consensus. When the disagreement between the two initial evaluators remained, a third evaluator (WB) decided whether to include the article in question.

The flowchart used shows the selection process in detail (Figure 1). We used PRISMA method to select the articles that were independently evaluated according to Strengthening the Reporting of Observational Studies in Epidemiology Statement (STROBE) by means of the evaluators (MD and BS).

Since the objectives, methods, and variables differed among the selected studies, it was not possible to compare them quantitatively. Therefore, some parameters including age, sex, diagnosis, pain intensity, frequency of attacks, medication, imaging techniques, tests performed, and main results were extracted and expressed in tables for qualitative data analysis.

\section{RESULTS}

The search culminated in 306 studies, of which nine articles were selected for qualitative synthesis. The included studies presented relevant quality according to STROBE, reaching the mean score of 16.7. In other words, the studies presented a mean of 16 items out of the 22 topics that form STROBE.

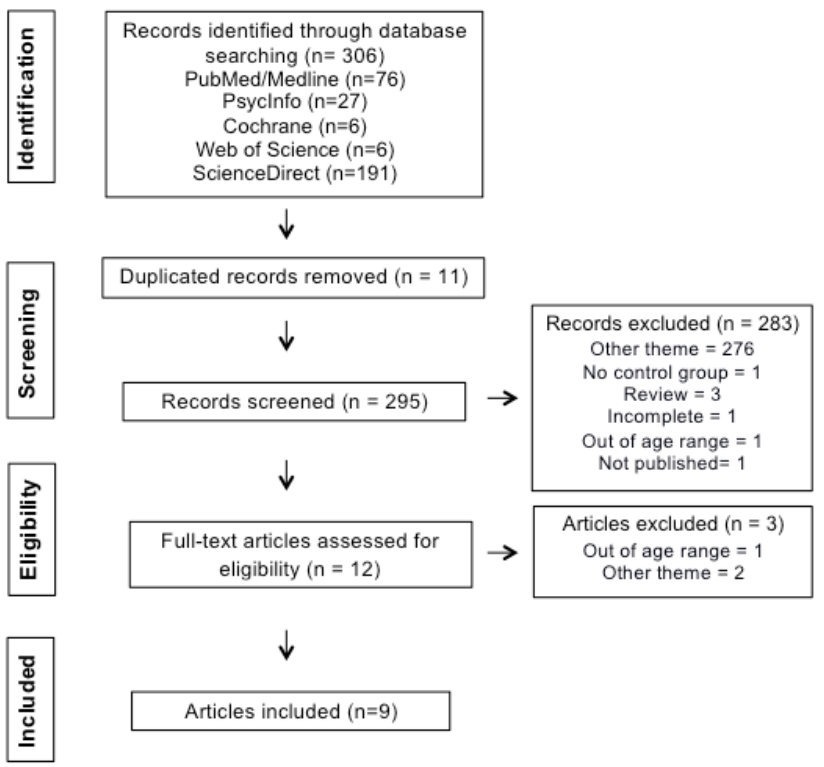

Figure 1. Eligibility of articles: flowchart. 
Regarding the studies evaluation, item-by-item of STROBE, a rate of $72.2 \%$ of agreements was reached between reviewers, representing a good validity among evaluators (Figure 2).

Regarding the characterization of individuals (Table 1), the sample totaled 201 individuals diagnosed with migraine and 182 individuals as the control group. Among the individuals suffering from migraine, women predominated $(n=194)$, with middle-aged adults presenting episodic migraine, moderate to severe pain intensity, predominance of migraine without aura, and mean duration of the condition, more than 10 years was found in most studies. Most studies also requested a pause in the migraine medication to prevent interferences during data collection.

Also in most of them, the link between migraine and cognitive performance was not analyzed. However, only one article has the goal of verifying cognitive alterations in individuals suffering from migraine ${ }^{35}$. On the other hand, some articles have made indirect associations in their discussion of neuroimaging findings with structures involved in cognitive functions, such as memory of pain ${ }^{36,37}$. Moreover, only five studies considered the ictal period of migraine ${ }^{35,38,39,40,41}$.

The types of memory addressed in the studies were visuospatial $^{40}$, memory process in general ${ }^{35,38,39,41,42}$, and memory of pain (painful stimuli generate maladaptative neuroplastic alterations, forming long-term memory and facilitating pain evocation $)^{36,37,43}$. The neuroimaging techniques that prevailed among the studies were structural MRI (Table 2) and functional MRI (Table 3) with the predominance of 3 Tesla equipment $^{35,36,37,38,39,40,41,42}$ and T1-weighted images ${ }^{36,37,38,39,40,41,42,43}$.

For the selected articles, neuroimaging studies focused on the effects under some physiological conditions, including resting state ${ }^{39,41}$, painful thermal stimula$\operatorname{tion}^{36,42}$, visual stimulation ${ }^{40}$, and verbal descriptors of pain ${ }^{43}$. Interestingly, those studies show that migraine changes the activity of structures related to memory processing and consolidation, such as the hippocampus ${ }^{36,37,42}$, insula ${ }^{38,39}$ and regions of the frontal ${ }^{36,40,41,42,43}$, parietal ${ }^{38,37,40,41}$ and temporal

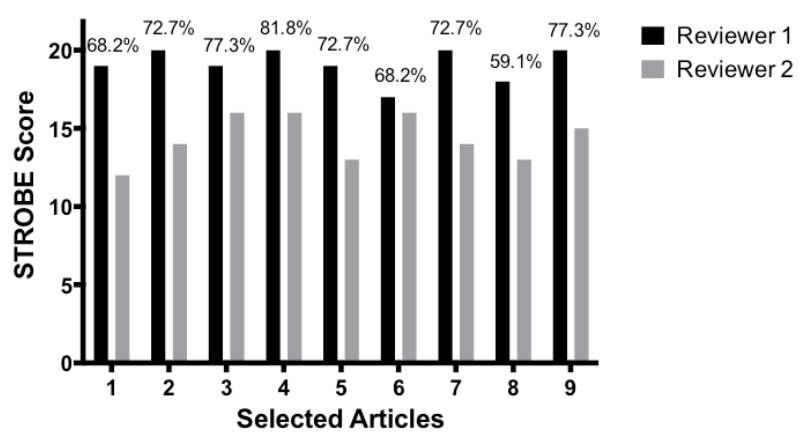

Source: Research data. The percentage values correspond to the percentage of agreement between the reviewers. Selected articles: 1=Wang et al. ${ }^{35}$; $2=$ Schwedt et al. ${ }^{36} ; 3=$ Liu et al. ${ }^{37} ; 4=$ Coppola et al. ${ }^{38} ; 5=$ Tso et al. ${ }^{39}$; $6=$ Hougaard et al. ${ }^{40} ; 7=$ Yang et al. ${ }^{41} ; 8=$ Maleki et al. ${ }^{42} ; 9=$ Eck et al. ${ }^{43}$. Figure 2. Evaluation of the selected articles according to the STROBE Statement. cortex ${ }^{36,37,38,39,42}$, suggesting an anatomical and/or functional association between migraine and memory.

Some studies decided to evaluate the individuals interictally (out of the migraine attack) ${ }^{35,38,39,40,41}$ or ictally (during the migraine attack) ${ }^{38}$, and others did not specify the moment in which neuroimaging took place ${ }^{36,37,42,43}$. In the ictal evaluation, increased gray matter density in the right lenticular nucleus, bilateral insula and left temporal pole were observed $^{38}$. In the interictal one, a reduction in gray matter density in the right inferior parietal lobe, right inferior temporal gyrus, right superior temporal gyrus and left temporal pole were observed ${ }^{38}$. The deep white matter of migraineurs presented more lesions in the lateral periphery of the ventricles and in the total white matter of the brain ${ }^{35}$.

Regarding functional imaging interictally, higher connectivity between the calcarine cortex, the Heschl gyrus and the right dorsal anterior insula was seen. The anterior right ventral insula presented increased connectivity with the left ventral medial part in individuals suffering from migraine, as well as with the left temporal lobe and the amygdala ${ }^{39}$. There were increased signs in the inferior frontal gyrus, superior parietal lobe; inferior parietal lobe and intraparietal sulcus, as well as the occipital cortex $\operatorname{areas}^{40}$. Moreover, individuals suffering from migraine presented several weaker neural connections, such as in the networks of dorsal attention, salience, default, visual and fronto-parietal modes ${ }^{41}$.

In the studies that did not specify the moment of image acquisition, changes in white matter, as well as decreased connection strength on insula, amygdala, cingulate gyrus, hippocampus, parahippocampal gyrus, striatum, orbitofrontal and prefrontal dorsolateral cortices, pre-central gyrus, inferior parietal gyrus, occipital and temporal cortices were observed $^{37,42}$. Individuals suffering from migraine had greater activation induced by pain in the lentiform nucleus, fusiform gyrus, subthalamic nucleus, hippocampus, mid-cingulate cortex, premotor, somatosensory and dorsolateral prefrontal cortex; and less activation in pre-central gyrus and superior temporal gyrus ${ }^{36}$. Adjectives related to pain provoked increased activations in the left orbitofrontal cortex and anterior insula during imaging, and in the right secondary somatosensory cortex and posterior insula during distraction when compared to negative adjectives ${ }^{43}$.

\section{DISCUSSION}

Neuroimaging findings suggest possible regions (hippocampus, insula, frontal, parietal, and temporal cortex) by which memory would be altered in individuals who suffer from migraine. These results support what was verified in studies that used cognitive tests and found alteration in prospective memory ${ }^{8}$, as well as in short- and long-term verbal $^{9,10}$ and visuo-spatial ${ }^{10}$ memories. Cerebral alterations, seen in imaging techniques, are verified in the ictal 


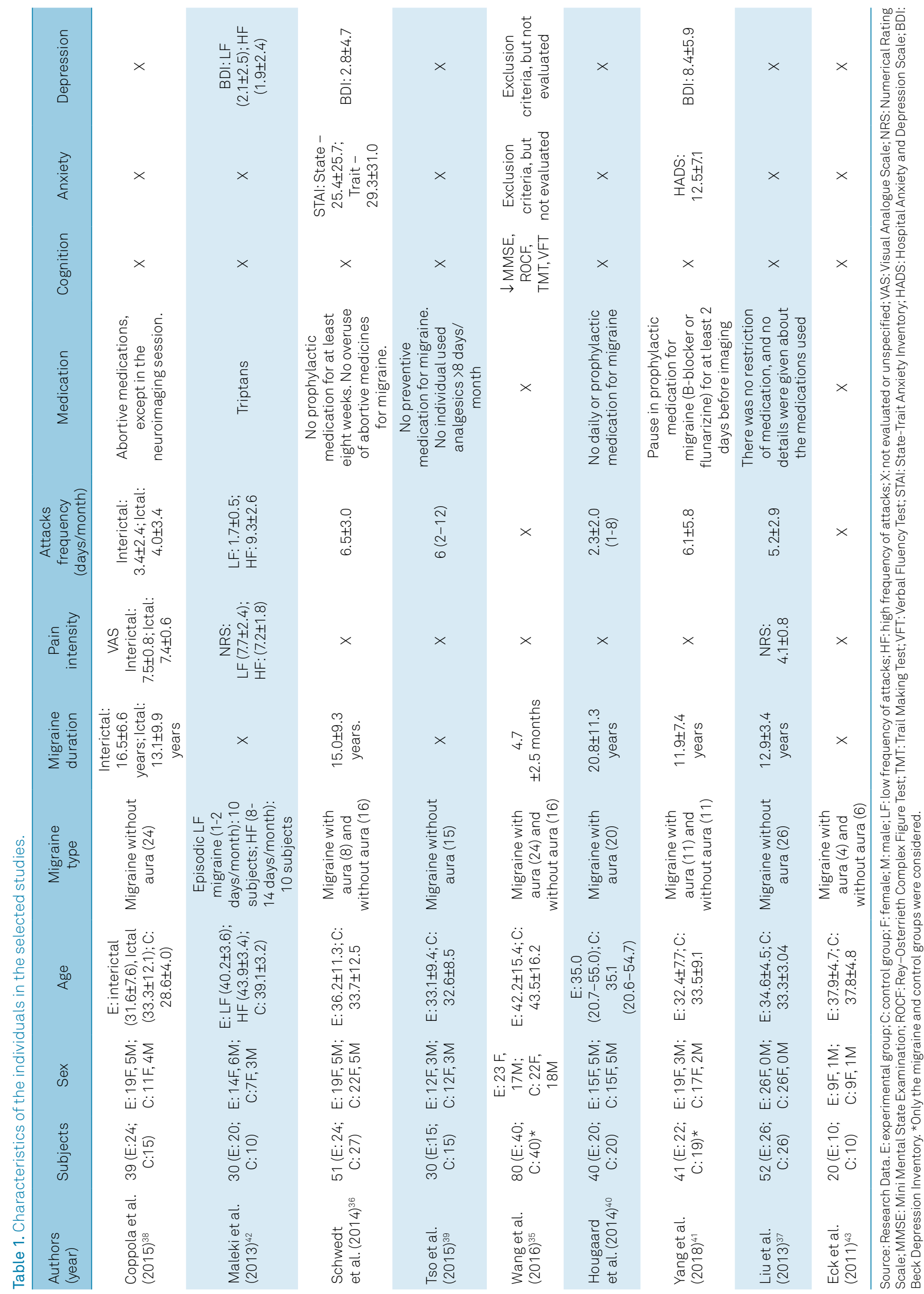


Table 2. Description of the results obtained with structural neuroimaging.

\begin{tabular}{|c|c|c|c|c|c|c|}
\hline $\begin{array}{l}\text { Authors } \\
\text { (year) }\end{array}$ & $\begin{array}{l}\text { Memory } \\
\text { type }\end{array}$ & $\begin{array}{l}\text { Ictal/interictal } \\
\text { condition }\end{array}$ & $\begin{array}{l}\text { Neuroimaging } \\
\text { instruments }\end{array}$ & $\begin{array}{l}\text { Task/Test } \\
\text { at imaging }\end{array}$ & Results & $\begin{array}{l}\text { Consequence } \\
\text { to memory }\end{array}$ \\
\hline $\begin{array}{l}\text { Coppola } \\
\text { et al. } \\
(2015)^{38}\end{array}$ & $\begin{array}{c}\text { Not } \\
\text { specified }\end{array}$ & $\begin{array}{l}\text { Ictal (10) and } \\
\text { Interictal (14) }\end{array}$ & $\begin{array}{l}\text { MRI, 3T, weighted } \\
\text { in T1. They did not } \\
\text { characterize the } \\
\text { pulse sequence. }\end{array}$ & $\begin{array}{c}\text { Not } \\
\text { applicable }\end{array}$ & $\begin{array}{l}\text { Reduction of gray matter density in } \\
\text { the mass of the right inferior parietal } \\
\text { lobe, right inferior temporal gyrus, } \\
\text { right superior temporal gyrus and } \\
\text { left temporal pole in individuals in } \\
\text { the interictal phase. } \\
\text { Increased gray matter density in the } \\
\text { right lenticular nucleus, bilateral } \\
\text { insula and left temporal pole in the } \\
\text { ictal phase. }\end{array}$ & $\begin{array}{l}\text { Dysfunction in } \\
\text { memory processing } \\
\text { by affecting regions, } \\
\text { such as the inferior } \\
\text { parietal lobe and } \\
\text { upper temporal } \\
\text { gyrus, areas that } \\
\text { interconnect } \\
\text { visual and auditory } \\
\text { processing, } \\
\text { perception and } \\
\text { memory. }\end{array}$ \\
\hline $\begin{array}{l}\text { Wang } \\
\text { et al. } \\
(2016)^{35}\end{array}$ & $\begin{array}{c}\text { Not } \\
\text { specified }\end{array}$ & Interictal & $\begin{array}{c}\text { MRI, 3T, Flair } \\
\text { weighted with } \\
\text { spin echo pulse } \\
\text { sequence, and T2. }\end{array}$ & $\begin{array}{c}\text { Not } \\
\text { applicable }\end{array}$ & $\begin{array}{l}\text { More lesions in the deep white } \\
\text { matter in the brain, in the lateral } \\
\text { periphery of the ventricles and in the } \\
\text { total white matter of the brain when } \\
\text { compared to the control group. }\end{array}$ & $\begin{array}{l}\text { Cognitive } \\
\text { impairment, } \\
\text { including memory, } \\
\text { related to lesions } \\
\text { of the brain white } \\
\text { matter. }\end{array}$ \\
\hline $\begin{array}{l}\text { Liu et al. } \\
(2013)^{37}\end{array}$ & $\begin{array}{c}\text { Memory of } \\
\text { pain }\end{array}$ & $x$ & $\begin{array}{l}\text { Diffusion } \\
\text { tensor imaging } \\
\text { tractography, MRI, } \\
\text { 3T, gradient echo } \\
\text { sequence. }\end{array}$ & $\begin{array}{c}\text { Not } \\
\text { applicable }\end{array}$ & $\begin{array}{l}\text { Changes in white matter; increase } \\
\text { of the clustering coefficient but } \\
\text { decrease in the modularity of } \\
\text { the networks; altered connection } \\
\text { strength on insula, amygdala, } \\
\text { cingulate gyrus, hippocampus, } \\
\text { parahippocampal gyrus, striatum, } \\
\text { prefrontal dorsolateral cortex, } \\
\text { pre-central gyrus, inferior parietal } \\
\text { gyrus, occipital cortices and } \\
\text { temporal cortices. }\end{array}$ & $\begin{array}{l}\text { Neurological } \\
\text { reorganization and } \\
\text { degeneration } \\
\text { in terms of learning } \\
\text { and memory, } \\
\text { especially related } \\
\text { to pain. }\end{array}$ \\
\hline
\end{tabular}

Source: Research Data.X: Not specified, MRI: Magnetic Resonance Imaging.

Table 3. Description of the results obtained with functional neuroimaging.

\begin{tabular}{lcccccc}
\hline $\begin{array}{l}\text { Authors } \\
\text { (year) }\end{array}$ & $\begin{array}{c}\text { Memory } \\
\text { type }\end{array}$ & $\begin{array}{c}\text { Ictal/interictal } \\
\text { condition }\end{array}$ & $\begin{array}{c}\text { Neuroimaging } \\
\text { instruments }\end{array}$ & $\begin{array}{c}\text { Task/Test } \\
\text { at imaging }\end{array}$ & Results & Consequence \\
to memory
\end{tabular}

Decreased functional connectivity with the hippocampus in the contralateral supramarginal gyrus, bilateral temporal pole, contralateral

fMRI, 3T, T1

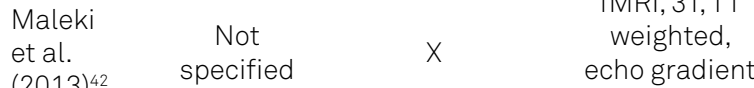
sequence.
Painful

thermal stimulation

orbitofrontal, bilateral nucleus

accumbens, bilateral anterior insula, bilateral medial frontal, contralateral paracingulate in individuals having a high frequency of migraine when compared to individuals having a low frequency of attacks.

Individuals having migraine had greater activation induced by pain in the lentiform nucleus, fusiform

fMRI, 3T, T1

Schwedt et al. $(2014)^{36}$ Memory of $x$ $x$ weighted with echo gradient sequence and T2 weighted with spin echo sequence.
Painful

thermal stimulation

gyrus, subthalamic nucleus, hippocampus, mid-cingulate cortex, premotor, somatosensory and dorsolateral prefrontal cortex and less activation in pre-central gyrus and superior temporal gyrus.

Higher connectivity between the calcarine cortex, the Heschl gyrus and the right dorsal anterior insula. Interictal (out Tso et al. Not of 72 hours $(2015)^{39} \quad$ specified before or after an attack).
fMRI, 3T, T2* weighted with planar echo sequence. Coregistration was performed with T1 weighted and echo gradient sequence.

\section{The anterior right ventral insula \\ Resting presented increased connectivity} state with the left ventral medial part in patients with migraine, as well as with the left temporal lobe and the amygdala.
Reduced connectivity of the hippocampus to other brain areas indicates possible memory-processing failure.

Most regions with increased pain induced activation participate in cognitive aspects of pain perception such as attention to pain and memory related to pain.

Alteration in the connectivity of the dorsal anterior insula would lead to a modification in the function of organizing and sustaining cognitive processing. 
Table 3. Continuation

\begin{tabular}{|c|c|c|c|c|c|c|}
\hline $\begin{array}{l}\text { Authors } \\
\text { (year) }\end{array}$ & $\begin{array}{l}\text { Memory } \\
\text { type }\end{array}$ & $\begin{array}{l}\text { Ictal/interictal } \\
\text { condition }\end{array}$ & $\begin{array}{l}\text { Neuroimaging } \\
\text { instruments }\end{array}$ & $\begin{array}{l}\text { Task/Test } \\
\text { at imaging }\end{array}$ & Results & $\begin{array}{c}\text { Consequence } \\
\text { to memory }\end{array}$ \\
\hline $\begin{array}{l}\text { Hougaard } \\
\text { et al. } \\
(2014)^{40}\end{array}$ & $\begin{array}{c}\text { Visuospatial } \\
\text { memory }\end{array}$ & Interictal & $\begin{array}{l}\text { fMRI-BOLD, 3T, } \\
\text { T1 weighted with } \\
\text { echo gradient } \\
\text { sequence. }\end{array}$ & $\begin{array}{c}\text { Visual } \\
\text { Stimulation }\end{array}$ & $\begin{array}{c}\text { Increased signs in the inferior frontal } \\
\text { gyrus, superior parietal lobe; inferior } \\
\text { parietal lobe and intraparietal } \\
\text { sulcus, as well as the occipital cortex } \\
\text { areas. }\end{array}$ & $\begin{array}{l}\text { Impairment of } \\
\text { the functional } \\
\text { network involved } \\
\text { in oculomotor } \\
\text { control, orientation } \\
\text { of movement, } \\
\text { perception of } \\
\text { movement, visual } \\
\text { attention, } \\
\text { and visuospatial } \\
\text { memory. }\end{array}$ \\
\hline $\begin{array}{l}\text { Yang et al. } \\
(2018)^{41}\end{array}$ & $\begin{array}{c}\text { Not } \\
\text { specified }\end{array}$ & $\begin{array}{l}\text { Interictal - } \\
\text { individuals } \\
\text { without } \\
\text { symptoms of } \\
\text { migraine two } \\
\text { days before } \\
\text { the application } \\
\text { of the imaging } \\
\text { technique. }\end{array}$ & $\begin{array}{l}\text { fMRI-BOLD, 3T. } \\
\text { Anatomical scan } \\
\text { T1 weighted with } \\
\text { echo gradient } \\
\text { sequence. } \\
\text { Spontaneous } \\
\text { activity measured } \\
\text { in T2 weighted } \\
\text { with echo gradient } \\
\text { sequence. }\end{array}$ & $\begin{array}{l}\text { Resting } \\
\text { state }\end{array}$ & $\begin{array}{l}\text { Patients having migraine presented } \\
\text { several weaker neural connections } \\
\text { than control. The most affected } \\
\text { functional brain networks were } \\
\text { dorsal attention, salience, default } \\
\text { mode, visual and fronto-parietal } \\
\text { modes. }\end{array}$ & $\begin{array}{l}\text { Changes in the } \\
\text { dorsal attention } \\
\text { network may } \\
\text { manifest as memory } \\
\text { deficits during and } \\
\text { between migraine } \\
\text { attacks. }\end{array}$ \\
\hline $\begin{array}{l}\text { Eck et al. } \\
(2011)^{43}\end{array}$ & $\begin{array}{l}\text { Memory of } \\
\text { pain }\end{array}$ & $x$ & $\begin{array}{l}\text { fMRI, } 1.5 \mathrm{~T}, \\
\text { weighted in } \mathrm{T} 1 \\
\text { and } \mathrm{T} 2 \text {. } \\
\text { They did not } \\
\text { characterize the } \\
\text { pulse sequence. }\end{array}$ & $\begin{array}{l}\text { Verbal } \\
\text { descriptors } \\
\text { of pain. }\end{array}$ & $\begin{array}{l}\text { Adjectives related to pain provoked } \\
\text { increased activations in the left } \\
\text { orbitofrontal cortex and anterior } \\
\text { insula during imaging, and in the } \\
\text { right secondary somatosensory } \\
\text { cortex and posterior insula during } \\
\text { distraction when compared to } \\
\text { negative adjectives. }\end{array}$ & $\begin{array}{l}\text { The involvement } \\
\text { of ventrolateral, } \\
\text { dorsolateral and } \\
\text { rostrolateral } \\
\text { and prefrontal } \\
\text { structures may } \\
\text { be related to } \\
\text { the demands } \\
\text { of imagination, } \\
\text { including processes } \\
\text { of working memory } \\
\text { and long-term } \\
\text { memory. }\end{array}$ \\
\hline
\end{tabular}

Source: research data. X: not specified; MRI: structural magnetic resonance imaging; fMRI: functional magnetic resonance imaging; $T=$ Tesla: BOLD: Blood-oxygen-level dependent imaging. *Only the migraine and control groups were considered.

and interictal state, demonstrating a possible "brain signature" attributed by migraine. This brain signature was verified by a study, which could differentiate individuals suffering from migraine from healthy ones, using resting-state fMRI. Migraineurs with longer disease duration were more accurately classified, suggesting that migraine generates maladaptative neuroplastic alterations ${ }^{31}$.

The major structures involved in acute pain processing are the primary and secondary somatosensory cortices, prefrontal, insular, anterior cingulate, and the thalamus ${ }^{44}$. Other less common areas are the basal ganglia, hippocampus, amygdala, cerebellum, and areas of temporal and parietal cortices. The activation of these structures depends on several factors, such as pain chronicity and the type of stim$\mathrm{uli}^{44,45}$. Therefore, memory dysfunctions would be the consequence of pain processing in the brain, because neural centers involved in sensory and/or affective property of pain sensation overlap memory centers ${ }^{5,6,7}$.

With respect to memory recovery, the activated brain regions are the medial and ventrolateral prefrontal cortex, the lateral and medial temporal cortex, retrosplenial cortex, posterior cingulate cortex, temporoparietal junction and the cerebellum. Other less common areas are the dorsolateral prefrontal cortex, medial superior and lateral superior cortex, anterior cingulate, medial orbitofrontal cortex, temporopolar and occipital cortex, thalamus, and amygdala, among oth$\mathrm{ers}^{46}$. Thus, it is observed that a significant number of structures are common to memory and pain networks (Figure 3).

Likewise, this interaction occurs in the process of pain memory, which is defended by a hypothesis of pain, learning and memory being intimately related. Fear to experience severe headache may stimulate memory and/or emotional network, which will then ultimately stimulate the pain network. Once facilitated, the pain network increases the frequency of migraine attacks by lowering the pain threshold and contributing to the chronification process. When these maladaptative neuroplastic alterations are implemented the condition turns into chronic migraine ${ }^{45}$.

The decreased functional connectivity ${ }^{42}$ and altered connection strength ${ }^{37}$ to the hippocampus, as well as its greater activation induced by pain ${ }^{37}$ lead to impairments in memory, since the hippocampus is classically known to be involved 
in memory consolidation and in learned behavior ${ }^{46}$. On the other hand, the insula integrates several systems, such as the nociceptive, visceral, limbic, and the prefrontal cortex ${ }^{47}$. In addition, the anterior dorsal insula is one of the responsible areas for organizing and sustaining cognitive processing ${ }^{48}$, making it a possible point of study to investigate memory changes in individuals suffering from migraine.

Components of the limbic system, such as prefrontal, cingulate, and insular cortices are activated in the affective processing of pain and memory. Moreover, limbic system components, such as the amygdala, have been related to persistent pain ${ }^{45}$. In terms of pain memory, the insula is activated when painful events are remembered and/or when pain is imagined. This emphasizes the notion that the pain share interoceptive and affective features. On the other hand, the parietal, temporal and frontal cortices, as well as subcortical structures (the amygdala and hippocampus, for example) would be related to explicit memory, also involved with pain memory ${ }^{11}$.

Moreover, the parietal and temporal lobes are associative regions acting in memory formation from auditory and visual perception and processing ${ }^{49}$. Alterations in these structures in migraine would lead to an overall dysfunction in sensory integration and memory processes ${ }^{50}$, which composes another pathway for studies in the area.

The presence of pain with a certain frequency can trigger maladaptive neuroplasticity of the central nervous system, reinforcing the process of painful chronification. Long-lasting pain causes modifications in brain areas cited in the review, an alteration that is worsened repeatedly during every migraine attack, maintaining or reinforcing the cognition/emotion of the pain experience. Thus, the brain can adapt itself to a state of frequent cortical overstimulation related to pain ${ }^{22,37}$.

These neuroplastic changes would be triggered by neurophysiological alterations resulting from the combination of learning, memory and pain processes ${ }^{39}$. In this scenario, metaplasticity occurs through previous or ongoing experiences that provoke changes in the sensory neocortex, reducing the induction of long-term potentiation (LTP) and increasing long-term depression (LTD) in synaptic responses ${ }^{51}$. LTP and LTD are established mechanisms in the learning and memory

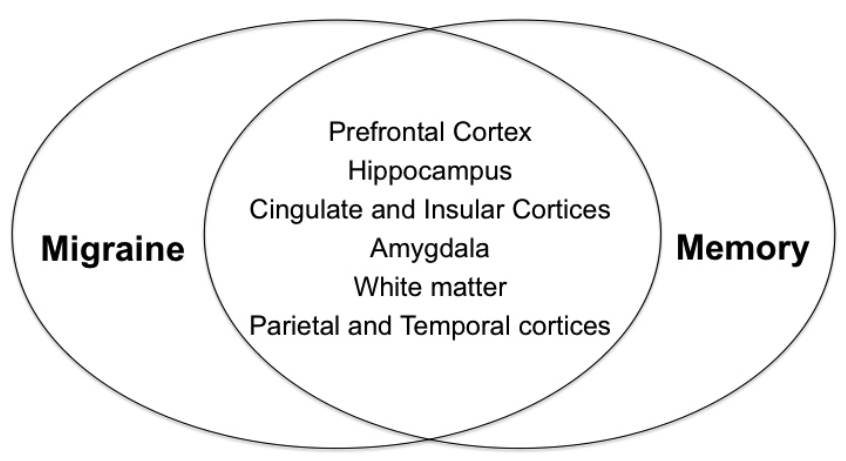

Figure 3. Common structures to memory and migraine. processes in the hippocampus and neocortex, and in the understanding of complex cognitive-emotional behaviors ${ }^{52}$.

As previously discussed in the studies, the prefrontal cortex contributes to memory processes ${ }^{36,37}$, thus some of its regions have been targeted for treating pain, such as the dorsolateral prefrontal cortex (DLPFC). Studies with Repetitive Transcranial Magnetic Stimulation (rTMS) observed analgesic effects of DLPFC on migraine. It would happen due to the top-down inhibition mode of DLPFC on the ascending midbrain-thalamic-cingulate pathway ${ }^{53}$. Moreover, benefits of rTMS in DLPFC are also seen for memory ${ }^{54}$.

Similarly, other therapeutic strategies, such as Mindfulness ${ }^{55,56}$, physical exercis ${ }^{57,58}$ and Transcranial Direct Current Stimulation on DLPFC optimize memory and promote analgesic effects ${ }^{59,60}$. However, as far as is known, there are no studies that simultaneously evaluate the repercussions of these therapies on memory and pain in individuals suffering from migraine.

Although these structures are mentioned in most of the selected studies, the relations between memory and migraine in most studies were assessed in an indirect way due to the scarcity of studies of neuroimaging directed to the memory of individuals suffering from migraine, which is one limitation of the present review. In addition, we did not find specify instruments to evaluate the quality of neuroimaging studies, demonstrating the importance of creating and validating such instruments for use in reviews.

\section{CONCLUSION}

We present the need for neuroimaging studies in individuals who have episodic and chronic migraine directed to memory by using appropriate cognitive tests for various memory types. There is a need for studies with larger samples and which correlate neuroimaging findings with clinical variables, such as pain intensity, frequency of attacks, use of medications and symptoms of anxiety and depression.

Despite this, this review achieve its goal of presenting morphological and functional changes in memory-related structures in individuals suffering from migraine. The results are expected to encourage researchers in developing new lines of thought about the etiology of the problem by instigating neuroimaging research for the study of memory processes in individuals suffering from migraine.

It may be suggested that the migrainous brain has some peculiarities when compared to the non-migrainous brain, being associated to global dysfunction of multisensory integration and memory processing. Migraine changes the activity of structures in various regions related to memory processing and consolidation, such as the hippocampus, insula, and regions of the frontal, parietal and temporal cortices, suggesting an anatomical and functional association between migraine and memory. However, it is necessary to carry out 
further studies with larger samples in association with specific cognitive tests, and without the interference of medications. Thus, once there are more concrete conclusions, there will be the possibility of the use of neuroimaging as an alternative to mark memory alterations and the early process of migraine chronification.

\section{ACKNOWLEDGEMENTS}

We thank Professor Paula Rejane Beserra Diniz, PhD of Universidade Federal de Pernambuco for her collaboration in discussing the technical aspects related to neuroimaging techniques.

\section{References}

1. World Health Organization. Headache disorders: fact sheet Updated April 2016. Available from: http://www.who.int/mediacentre/ factsheets/fs277/en/

2. Martins IP, Gil-Gouveia R, Silva C, Maruta C, Oliveira AG. Migraine, headaches, and cognition. Headache. 2012 Nov-Dec;52(10):1471-82. https://doi.org/10.1111/j.1526-4610.2012.02218.x

3. Araújo CM, Barbosa IG, Lemos SMA, Domingues RB, Teixeira AL. Cognitive impairment in migraine: a systematic review. Dement Neuropsychol. 2012 Apr-Jun;6(2):74-9. https://doi.org/10.1590/ S1980-57642012DN06020002

4. Calandre EP, Bembibre J, Arnedo ML, Becerra D. Cognitive disturbances and regional cerebral blood flow abnormalities in migraine patients: their relationship with the clinical manifestations of the illness. Cephalalgia. 2002 May;22(4):291-302. https://doi. org/10.1046/j.1468-2982.2002.00370.x

5. Gil-Gouveia R, Oliveira AG, Martins IP. Assessment of cognitive dysfunction during migraine attacks: a systematic review. J Neurol. 2015 Mar;262(3):654-65. https://doi.org/10.1007/s00415-0147603-5

6. Mathur VA, Khan SA, Keaser ML, Hubbard CS, Goyal M, Seminowicz DA. Altered cognition-related brain activity and interactions with acute pain in migraine. Neuroimage Clin. 2015 Jan;7:347-58. https:// doi.org/10.1016/j.nicl.2015.01.003

7. Moriarty O, McGuire BE, Finn DP. The effect of pain on cognitive function: a review of clinical and preclinical research. Prog Neurobiol. 2011 Mar;93(3):385-404. https://doi.org/10.1016/j. pneurobio.2011.01.002

8. Santangelo G, Russo A, Tessitore A, Garramone F, Silvestro M, Della Mura MR, et al. Prospective memory is dysfunctional in migraine without aura. Cephalalgia. 2018 Oct;38(12):1825-32. https://doi. org/10.1177/0333102418758280

9. Kalaydjian A, Zandi PP, Swartz KL, Eaton WW, Lyketsos C. How migraines impact cognitive function: findings from the Baltimore ECA. Neurology. 2007 Apr;68(17):1417-24. https://doi.org/10.1212/01. wnl.0000268250.10171.b3

10. Le Pira F, Zappalà G, Giuffrida S, Lo Bartolo ML, Reggio E, Morana $\mathrm{R}$, et al. Memory disturbances in migraine with and without aura: a strategy problem? Cephalalgia. 2000 Jun;20(5):475-8. https://doi. org/10.1046/j.1468-2982.2000.00074.x

11. Upadhyay J, Granitzka J, Bauermann T, Baumgärtner U, Breimhorst $\mathrm{M}$, Treede RD, et al. Detection of central circuits implicated in the formation of novel pain memories. J Pain Res. 2016 Sep;9:671-81. https://doi.org/10.2147/JPR.S113436

12. Huang L, Dong HJ, Wang X, Wang Y, Xiao Z. Duration and frequency of migraines affect cognitive function: evidence from neuropsychological tests and event-related potentials. J Headache Pain. 2017 May;18(1):54. https://doi.org/10.1186/s10194-017-0758-6

13. Pellegrino Baena C, Goulart AC, Santos IS, Suemoto CK, Lotufo PA, Bensenor IJ. Migraine and cognitive function: Baseline findings from the Brazilian Longitudinal Study of Adult Health: ELSA-Brasil. Cephalalgia. 2018 Aug;38(9):1525-34. https://doi. org/10.1177/0333102417737784
14. Poldrack RA, Packard MG. Competition among multiple memory systems: converging evidence from animal and human brain studies. Neuropsychologia. 2003;41(3):245-51. https://doi. org/10.1016/s0028-3932(02)00157-4

15. Squire LR, Kandel ER. Memory from mind to molecules. New York: Scientific American Library, 1999.

16. McGaugh JL. Memory: a century of consolidation. Science. 2000 Jan;287(5451):248-51. https://doi.org/10.1126/science.287.5451.248

17. Kim JJ, Diamond DM. The stressed hippocampus, synaptic plasticity and lost memories. Nat Rev Neurosci. 2002 Jun;3(6):453-62. https:// doi.org/10.1038/nrn849

18. Flor $\mathrm{H}$. The functional organization of the brain in chronic pain. Prog Brain Res. 2000;129:313-22. https://doi.org/10.1016/S00796123(00)29023-7

19. Wang L, Gui P, Li L, Ku Y, Bodner M, Fan G, et al. Neural correlates of heat-evoked pain memory in humans. J Neurophysiol. 2016 Mar;115(3):1596-604. https://doi.org/10.1152/jn.00126.2015

20. Lobanov OV, Zeidan F, McHaffie JG, Kraft RA, Coghill RC. From cue to meaning: brain mechanisms supporting the construction of expectations of pain. Pain. 2014 Jan;155(1):129-36. https://doi. org/10.1016/j.pain.2013.09.014

21. Choi DS, Choi DY, Whittington RA, Nedeljković SS. Sudden amnesia resulting in pain relief: the relationship between memory and pain. Pain. 2007 Nov;132(1-2):206-10. https://doi.org/10.1016/j.pain.2007.06.025

22. Maleki N, Becerra L, Nutile L, Pendse G, Brawn J, Bigal M, et al. Migraine attacks the basal ganglia. Mol Pain. 2011 Sep;7:71. https:// doi.org/10.1186/1744-8069-7-71

23. Öze A, Nagy A, Benedek G, Bodosi B, Kéri S, Pálinkás É, et al. Acquired equivalence and related memory processes in migraine without aura. Cephalalgia. 2017 May;37(6):532-40. https://doi. org/10.1177/0333102416651286

24. Ghadiri MK, Kozian M, Ghaffarian N, Stummer W, Kazemi H, Speckmann EJ, et al. Sequential changes in neuronal activity in single neocortical neurons after spreading depression. Cephalalgia. 2012 Jan;32(2):116-24. https://doi.org/10.1177/0333102411431308

25. Martens-Mantai T, Speckmann EJ, Gorji A. Propagation of cortical spreading depression into the hippocampus: The role of the entorhinal cortex. Synapse. 2014 Dec;68(12):574-84. https://doi. org/10.1002/syn.21769

26. Mesgari M, Ghaffarian N, Khaleghi Ghadiri M, Sadeghian H, Speckmann EJ, Stummer W, et al. Altered inhibition in the hippocampal neural networks after spreading depression. Neuroscience. 2015 Sep 24;304:190-7. https://doi.org/10.1016/j. neuroscience.2015.07.035

27. Wernsmann B, Pape HC, Speckmann EJ, Gorji A Effect of cortical spreading depression on synaptic transmission of rat hippocampal tissues. Eur J Neurosci. 2006 Mar;23(5):1103-10. https://doi. org/10.1111/j.1460-9568.2006.04643.x

28. Gorgolewski KJ, Auer T, Calhoun VD, Craddock RC, Das S, Duff EP, et al. The brain imaging data structure, a format for organizing and describing outputs of neuroimaging experiments. Sci Data. 2016 Jun;3:160044. https://doi.org/10.1038/sdata.2016.44 
29. Mainero C, Boshyan J, Hadjikhani N. Altered functional magnetic resonance imaging resting-state connectivity in periaqueductal gray networks in migraine. Ann Neurol. $2011 \mathrm{Nov}$;0(5):838-45. https:// doi.org/10.1002/ana.22537

30. Jin C, Yuan K, Zhao L, Zhao L, Yu D, von Deneen KM, et al. Structural and functional abnormalities in migraine patients without aura. NMR Biomed. 2013 Jan;26(1):58-64. https://doi.org/10.1002/nbm.2819

31. Chong CD, Gaw N, Fu Y, Li J, Wu T, Schwedt TJ. Migraine classification using magnetic resonance imaging resting-state functional connectivity data. Cephalalgia. 2017 Aug;37(9):828-44. https://doi. org/10.1177/0333102416652091

32. Coppola G, Tinelli E, Lepre C, lacovelli E, Di Lorenzo C, Di Lorenzo G, et al Dynamic changes in thalamic microstructure of migraine without aura patients: a diffusion tensor magnetic resonance imaging study. Eur J Neurol. 2014 Feb;21(2):287-e13. https://doi.org/10.1111/ ene.12296

33. Higgins JPT, Green S. Cochrane handbook for systematic reviews of interventions. Chichester, UK: John Wiley \& Sons, 2008.

34. Moher D, Liberati A, Tetzlaff J, Altman DG, PRISMA Group. Preferred reporting items for systematic reviews and meta-analyses: the PRISMA statement. Ann Intern Med. 2009 Aug;151(4):264-9. https:// doi.org/10.7326/0003-4819-151-4-200908180-00135

35. Wang $\mathrm{N}$, Huang $\mathrm{HL}$, Zhou H, Yu CY. Cognitive impairment and quality of life in patients with migraine-associated vertigo. Eur Rev Med Pharmacol Sci. 2016 Dec;20(23):4913-7.

36. Schwedt TJ, Chong CD, Chiang CC, Baxter L, Schlaggar BL, Dodick DW. Enhanced pain-induced activity of pain-processing regions in a case-control study of episodic migraine. Cephalalgia. 2014 Oct;34(12):947-58. https://doi.org/10.1177/0333102414526069

37. Liu J, Zhao L, Nan J, Li G, Xiong S, von Deneena KM, et al. The trade-off between wiring cost and network topology in white matter structural networks in health and migraine. Exp Neurol. 2013 Oct;248:196-204. https://doi.org/10.1016/j.expneurol.2013.04.012

38. Coppola G, Di Renzo A, Tinelli E, lacovelli E, Lepre C, Di Lorenzo C, et al. Evidence for brain morphometric changes during the migraine cycle: a magnetic resonance-based morphometry study. Cephalalgia. 2015 Aug;35(9):783-91. https://doi.org/10.1177/0333102414559732

39. Tso AR, Trujillo A, Guo CC, Goadsby PJ, Seeley WW. The anterior insula shows heightened interictal intrinsic connectivity in migraine without aura. Neurology. 2015 Mar;84(10):1043-50. https://doi. org/10.1212/WNL.0000000000001330

40. Hougaard A, Amin FM, Hoffmann MB, Rostrup E, Larsson HB, Asghar $M S$, et al. Interhemispheric differences of $\mathrm{fMRI}$ responses to visual stimuli in patients with side fixed migraine aura. Hum Brain Mapp. 2014 Jun;35(6):2714-23. https://doi.org/10.1002/hbm.22361

41. Yang FC, Chou KH, Hsu AL, Fuh JL, Lirng J, Kao HW, et al. Altered brain functional connectome in migraine with and without restless legs syndrome: a resting-state functional MRI study. Front Neurol. 2018 Jan;9:25. https://doi.org/10.3389/fneur.2018.00025

42. Maleki N, Becerra L, Brawn J, McEwen B, Burstein R, Borsook D. Common hippocampal structural and functional changes in migraine. Brain Struct Funct. 2013 Jul;218(4):903-12. https://doi. org/10.1007/s00429-012-0437-y

43. EckJ, Richter M, Straube T, Miltner WH, Weiss T. Affective brain regions are activated during the processing of pain-related words in migraine patients. Pain. 2011 May;152(5):1104-13. https://doi. org/10.1016/j.pain.2011.01.026

44. Prakash S, Golwala P. Phantom headache: pain-memory-emotion hypothesis for chronic daily headache? J Headache Pain. 2011 Jun;1(3): 281-6. https://doi.org/10.1007/s10194-011-0307-7

45. Svoboda E, McKinnon MC, Levine B. The functional neuroanatomy of autobiographical memory: a meta-analysis. Neuropsychologia.
2006 Jun;44(12):2189-208. https://doi.org/10.1016/j. neuropsychologia.2006.05.023

46. van der Flier WM, Scheltens P Alzheimer disease: hippocampal volume loss and Alzheimer disease progression. Nat Rev Neurol. 2009 Jul;5(7):361-2. https://doi.org/10.1038/nrneurol.2009.94

47. Craig AD How do you feel? Interoception: the sense of the physiological condition of the body. Nat Rev Neurosci. 2002 Aug;3(8):655-66. https://doi.org/10.1038/nrn894

48. Dosenbach NU, Fair DA, Miezin FM, Cohen AL, Wenger KK, Dosenbach RA, et al. Distinct brain networks for adaptive and stable task control in humans. Proc Natl Acad Sci USA. 2007 Jun;104(26):11073-8. https://doi.org/10.1073/pnas.0704320104

49. Kravitz D, Saleem KS, Baker Cl, Ungerleider LG, Mishkin M. The ventral visual pathway: An expanded neural framework for the processing of object quality. Trends Cogn Sci. 2013 Jan;17(1):26-49. https://doi.org/10.1016/j.tics.2012.10.011

50. Singh-Curry $V$, Husain M. The functional role of the inferior parietal lobe in the dorsal and ventral stream dichotomy. Neuropsychologia. 2009 May;47(6):1434-48. https://doi.org/10.1016/j. neuropsychologia.2008.11.033

51. Clem RL, Celikel T, Barth AL. Ongoing in vivo experience triggers synaptic metaplasticity in the neocortex. Science. 2008 Jan;319(5859):101-4. https://doi.org/10.1126/science.1143808

52. Magerl W, Hansen N, Treede RD, Klein T. The human pain system exhibits higher-order plasticity (metaplasticity). Neurobiol Learn Mem. 2018 Oct;154:112-120. https://doi.org/10.1016/j. $n ! m .2018 .04 .003$

53. Brighina F, De Tommaso M, Giglia F, Scalia S, Cosentino G, Puma A, et al Modulation of pain perception by transcranial magnetic stimulation of left prefrontal cortex.J Headache Pain. 2011 Apr;12(2):185-91. https://doi.org/10.1007/s10194-011-0322-8

54. Gagnon G, Blanchet S, Grondin S, Schneider C. Paired-pulse transcranial magnetic stimulation over the dorsolateral prefrontal cortex interferes with episodic encoding and retrieval for both verbal and non-verbal materials. Brain Res. 2010 Jul;1344:148-58. https:// doi.org/10.1016/j.brainres.2010.04.041

55. Mrazek MD, Franklin MS, Phillips DT, Baird B, Schooler JW. Mindfulness training improves working memory capacity and GRE performance while reducing mind wandering. Psychol Sci. 2013 May;24(5):776-81. https://doi.org/10.1177/0956797612459659

56. Grazzi L, Sansone E, Raggi A, D’Amico D, De Giorgio A, et al. Mindfulness and pharmacological prophylaxis after withdrawal from medication overuse in patients with Chronic Migraine: an effectiveness trial with a one-year follow-up. J Headache Pain. 2017 Feb;18(1):15. https://doi.org/10.1186/s10194-017-0728-z

57. Irby MB, Bond DS, Lipton RB, Nicklas B, Houle TT, Penzien DB. Aerobic exercise for reducing migraine burden: mechanisms, markers, and models of change processes. Headache. 2016 Feb;56(2):357-69. https://doi.org/10.1111/head.12738

58. Hötting K, Schickert N, Kaiser J, Röder B, Schmidt-Kassow M. The effects of acute physical exercise on memory, peripheral BDNF, and cortisol in young adults. Neural Plast. 2016;6860573:1-12. https:// doi.org/10.1155/2016/6860573

59. Vecchio E, Ricci K, Montemurno A, Delussi M, Invitto S, De Tommaso M. Effects of left primary motor and dorsolateral prefrontal cortex transcranial direct current stimulation on laser-evoked potentials in migraine patients and normal subjects. Neurosci Lett. 2016 Jul;626:149-57. https://doi.org/10.1016/j.neulet.2016.05.034

60. Ohn SH, Park Cl, Yoo WK, Ko MH, Choi KP, Kim GM, et al. Timedependent effect of transcranial direct current stimulation on the enhancement of working memory. Neuroreport. 2008 Jan;19(1):43-7. https://doi.org/10.1097/WNR.0b013e3282f2adfd 